\title{
PICK1 Mediates Synaptic Recruitment of AMPA Receptors at Neurexin-Induced Postsynaptic Sites
}

\author{
Junyu Xu, ${ }^{1,2}$ Chuen Kam, ${ }^{1}$ Jian-hong Luo, ${ }^{2}$ and Jun Xia ${ }^{1}$ \\ ${ }^{1}$ Division of Life Science, Division of Biomedical Engineering and State Key Laboratory of Molecular Neuroscience, The Hong Kong University of Science \\ and Technology, Clear Water Bay, Kowloon, Hong Kong 100044, People’s Republic of China, and 2Department of Neurobiology, Key Laboratory of Medical \\ Neurobiology of Ministry of Health, Zhejiang Province Key Laboratory of Neurobiology, Zhejiang University School of Medicine, Hangzhou, Zhejiang \\ 310058, People's Republic of China
}

In the CNS, synapse formation and maturation play crucial roles in the construction and consolidation of neuronal circuits. Neurexin and neuroligin localize on the opposite sides of synaptic membrane and interact with each other to promote the assembly and specialization of synapses. However, the excitatory synapses induced by the neurexin-neuroligin complex are initially immature synapses that lack AMPA receptors. Previously, PICK1 (protein interacting with C kinase 1) was shown to cluster and regulate the synaptic localization of AMPA receptors. Here, we report that during synaptogenesis induced by neurexin in cultured neurons from rat hippocampus, PICK1 recruited AMPA receptors to immature postsynaptic sites. This synaptic recruitment of AMPA receptors depended on the interaction between GluA2 and PICK1, and on the lipid-binding ability of PICK1, but not the interaction between PICK1 and neuroligin. Last, our results demonstrated that the recruitment of GluA2 to synapses could be prevented by ICA69 (islet cell autoantigen $69 \mathrm{kDa}$ ), a key binding partner of PICK1. Our study showed that PICK1, being negatively regulated by ICA69, could facilitate synapse maturation.

Key words: AMPA receptor; neurexin; neuroligin; PICK1; silent synapse; synapse maturation

\section{Introduction}

Synapse formation and maturation play critical roles in the formation of neuronal circuits and in learning and memory. Neurexins and neuroligins constitute one of the important cell adhesion molecule complexes for synapse assembly in the CNS. In a pontine axon-HEK293T coculture system, neuroligin 1 (NL1) induced the assembly of presynaptic structures by binding with neurexin (Scheiffele et al., 2000). Similarly, neurexin $1 \beta$ induces postsynaptic structures by triggering neuroligin clustering (Graf et al., 2004; Nam and Chen, 2005). Further studies revealed the essential roles of neurexin and neuroligin in synaptic transmission and brain function. In mice featuring triple knockouts of neuroligin or $\alpha$-neurexin genes, severe defects in synaptic transmission were observed (Missler et al., 2003; Varoqueaux et al.,

\footnotetext{
Received Jan. 21, 2014; revised 0ct. 6, 2014; accepted 0ct. 9, 2014.

Author contributions: J. Xia designed research; J. Xu and C.K. performed research; J. Xu, C.K., J.-h.L., and J. Xia analyzed data; J. Xu and J. Xia wrote the paper.

This work was supported in part by the Research Grants Council of the Hong Kong Special Administrative Region, People's Republic of China (Grants 663310, 663613, HKUST10/CRF/12R, CUHK2/CRF/11G, T13-607/12R, and AoE/ M-05/12), the National Natural Science Foundation of China (Grants 91232303 and 81201008), the National Key Basic Research Program of China (Grants 2013 CB530900 and 2010CB912002), and the Zhejiang Provincial Natural Science Foundation of China (Grants LY12C09001). We thank W. Tung, C. He, and P. leong for their technical assistance; Dr. Ann M. Craig (University of British Columbia, Vancouver, BC, Canada) for providing the CFP-tagged neurexin $1 \beta$ and YFP-tagged neuroligin 1 constructs; and Dr. D. Chang (The Hong Kong University of Science and Technology) for providing the $\mathrm{pECFP(3}$ vector.

The authors declare no competing financial interests.

Correspondence should be addressed to Dr. Jun Xia, Division of Life Science, Division of Biomedical Engineering and State Key Laboratory of Molecular Neuroscience, the Hong Kong University of Science and Technology, Clear Water Bay, Kowloon, Hong Kong 100044, People's Republic of China. E-mail: jxia@ust.hk.

DOI:10.1523/JNEUROSCI.0296-14.2014

Copyright $\odot 2014$ the authors $\quad 0270-6474 / 14 / 3415415-10 \$ 15.00 / 0$
}

2006). Altered expression levels of neuroligins led to learning defects or impaired social interactions in mice (Hines et al., 2008; Kim et al., 2008b). Mutations of human neurexin and neuroligin genes were found to be associated with autism spectrum disorders and mental retardation (Jamain et al., 2003; Laumonnier et al., 2004; Feng et al., 2006; Arking et al., 2008; Kim et al., 2008a; Yan et al., 2008a,b). Furthermore, mouse models of neuroligin mutations showed social interaction defects similar to those recorded in autistic patients (Tabuchi et al., 2007; Etherton et al., 2011).

Intriguingly, neurexin-induced excitatory synapses lack AMPA receptors (Graf et al., 2004). Excitatory synapses without AMPA receptors are regarded as silent synapses (Isaac et al., 1995; Liao et al., 1995). Although in neuroligin1 knock-out mice, 3-8 weeks of age, hippocampal AMPA-mediated transmission remains intact (Chubykin et al., 2007; Blundell et al., 2010), the synaptic AMPA receptor level and AMPA receptor-mediated synaptic transmission were diminished in the newborns (Mondin et al., 2011). In addition, neuroligin3 deficiency in Purkinje cells alters the level of basal phosphorylation of GluA2 S880 residue, which abolishes mGluR-dependent long-term depression (LTD; Baudouin et al., 2012).

Previously, PICK1 (protein interacting with C kinase 1) was identified to interact with AMPA receptor subunits GluA2/3/4c (Dev et al., 1999; Xia et al., 1999). PICK1 mediates AMPA receptor surface expression (Chung et al., 2000; Perez et al., 2001) and trafficking during both LTD and long-term potentiation (Xia et al., 2000; Steinberg et al., 2006; Terashima et al., 2008). Overexpression of PICK1 in hippocampal neurons increases GluA2 levels at synapses in a lipid binding-dependent manner, revealing a 
potential role of PICK1 in maintaining a synaptic pool of AMPA receptors (Jin et al., 2006).

AMPA receptors were detected in neuroligin-induced synapses after spine formation (Nam and Chen, 2005). However, the underlying mechanism remains unclear. Here, we report that overexpressed PICK1 was enriched at neurexin $1 \beta$-induced synapses and recruited AMPA receptors to postsynaptic sites. We also found that the interaction between GluA2 and PICK1, as well as the lipid-binding ability of PICK1, were necessary for the synaptic recruitment of AMPA receptors. Furthermore, ICA69 (islet cell autoantigen $69 \mathrm{kDa}$ ), a PICK1 binding partner, prevented the synaptic recruitment of AMPA receptors by restricting the localization of PICK1 to dendritic shafts.

\section{Materials and Methods}

Plasmids. CFP-tagged neurexin $1 \beta$ and YFP-tagged neuroligin 1 constructs were provided by Dr. Ann M. Craig (University of British Columbia, Vancouver, BC, Canada; Graf et al., 2004). HA-tagged or GFP-tagged PICK1 constructs were generated by splicing the PICK1 cDNA out of the myc-pRK5 vector described previously (Xia et al., 1999) and subcloning the cDNA into an HA-pRK5 vector or a modified pEGFPC3 vector (catalog \#6082-1, Clontech) by using SalI/NotI sites. CFP-tagged PICK1 was generated by splicing out PICK1 sequences from a pEGFPC3 vector and inserting them into a pECFPC3 vector (from Dr. D. Chang, Hong Kong University of Science and Technology) by using SalI/BamHI sites. PICK1 $\mathrm{KD}-\mathrm{AA}$ and $\mathrm{K} 266 \mathrm{E} / \mathrm{K} 268 \mathrm{E}$ (2KE) mutants were generated using sitedirected mutagenesis as previously described (Jin et al., 2006). Rat ICA69 cDNA was generated as previously described in the myc-pRK5 vector (Cao et al., 2007). All constructs were verified using PCR sequencing.

Antibodies. A mouse monoclonal postsynaptic density-95 (PSD-95) antibody (MAB1596, Millipore Bioscience Research Reagents) was used as a postsynaptic marker, and a mouse monoclonal SV2 (synaptic vesicle 2) antibody [SV2, The Developmental Studies Hybridoma Bank at the University of Iowa (DSHB)] and a rabbit polyclonal synapsin 1 antibody (S193, Sigma) were used as presynaptic markers. Mouse monoclonal myc antibody (9E10) was purchased from DSHB. A cy3-conjugated rabbit GluA2 primary antibody, provided by Professor D. Liao (University of Minnesota, Minneapolis, MN; Liao et al., 1999), was used for the detection of endogenous GluA2 in neurons. Unlabeled rabbit GluA2 antibodies were generated by injecting New Zealand White rabbits with a synthesized GluA2 C-terminal 20 aa peptide. The GluA2 antibodies were affinity purified using the antigenic peptide coupled to Affigel beads (catalog \#153-6099, Bio-Rad) and were used for the detection of overexpressed GluA2 proteins in HEK293T cells. Rabbit polyclonal GluA1 peptide antibody was generated against $\mathrm{N}$-terminal residues 269-287 of rat GluA1. Guinea pig PICK1 antibody was generated in Hartley guinea pigs against the C-terminal 100 aa of mouse PICK1 (PC100) linked to a Histag and then purified using GST-tagged PC100. Rabbit ICA69 antibody was generated against a His-tagged fusion protein of rat ICA69 (residues 215-480). Rhodamine RedX-conjugated secondary antibodies were purchased from Jackson ImmunoResearch, and Alexa Fluor 488-conjugated and Alexa Fluor 647-conjugated secondary antibodies were purchased from Molecular Probes.

Generation of Sindbis viruses. GFP-tagged PICK1 or GFP were subcloned into the pSinRep5 viral vector containing viral replication and packaging sequences (catalog \#K75001, Life Technologies). The pSinRep5 constructs and the DH26S helper DNA containing viral structural sequences (catalog \#K75001, Life Technologies) were then transcribed in vitro into mRNAs by using an SP6 promoter in vitro transcription kit (catalog \#1340, Ambion). The mRNAs were transfected into BHK cells at a 1:1 ratio using Lipofectamine 2000 (catalog \#52887, Life Technologies). Culture media containing viral particles released from the BHK cells were collected and centrifuged briefly at $2000 \mathrm{rpm}$ to remove cell debris, and viral particles were then concentrated by centrifuging the media at $20,000 \times g$ for $4 \mathrm{~h}$ and stored at $-80^{\circ} \mathrm{C}$. To infect neurons, the viruses were added directly to the culture media at a titer determined for each batch of the viruses.
Cell coculture and transfection. Cultured hippocampal neurons were prepared from embryonic day 18 rats (Sprague Dawley) of either sex and grown on coverslips coated with poly-L-lysine (Sigma) at a density of 0.02 million cells $/ \mathrm{cm}^{2}$. Hippocampal neurons were cultured in Neurobasal Media (Life Technologies) containing the B27 supplement (Life Technologies) and 2 mM Glutamax (Life Technologies). COS7 cells were cultured in MEM media (Life Technologies) containing 10\% fetal bovine serum (Life Technologies) and penicillin/streptomycin/glutamine (Life Technologies). To prepare cocultures, COS7 cells were transfected using Lipofectamine 2000 (Life Technologies) $1 \mathrm{~d}$ before neuronal infection, and the hippocampal neurons were infected with the Sindbis viruses between 14 and $15 \mathrm{~d}$ in vitro; 6-7 h after neuronal infection, the COS7 cells were resuspended using $0.05 \%$ trypsin digestion, washed once with PBS, and then plated onto the hippocampal neurons. Cells were cocultured for $14-16 \mathrm{~h}$, and then immunostained and analyzed using fluorescence microscopy. HEK293T cells were cultured in the same media as COS7 cells were. Before transfection, HEK293T cells were grown on coverslips coated with $0.2 \%$ gelatin, and the cDNA constructs encoding GluA2- and CFP-tagged PICK1 together with or without YFP-tagged neuroligin1 were transfected into the HEK293T cells by using calcium phosphate coprecipitation. Cells were immunostained 36-48 h after transfection and then used for imaging analysis. Neurons at a density of 0.04 million cells $/ \mathrm{cm}^{2}$ were transfected at $5-7 \mathrm{~d}$ in vitro. CFP-PICK1, with or without YFP-tagged NL1 (YFP-NL1), was transfected into hippocampal neurons by using calcium phosphate coprecipitation, and cocultures were prepared at $14-15 \mathrm{~d}$ in vitro.

Immunocytochemistry. Cells grown on coverslips were fixed using $4 \%$ paraformaldehyde in PBS containing 4\% sucrose for $15 \mathrm{~min}$ at room temperature, and then permeabilized using $0.2 \%$ Triton X-100 for 10 min at $4^{\circ} \mathrm{C}$. After blocking with $10 \%$ normal donkey serum (NDS) for $>2$ $\mathrm{h}$ at room temperature, the cells were incubated for $1 \mathrm{~h}$ with various primary antibodies diluted in 3\% NDS. After washing for three times with PBS, fluorescent secondary antibodies were applied at room temperature for $1 \mathrm{~h}$. After washing, the coverslips were mounted using PermaFluor (Thermo Scientific) and observed under a fluorescence microscope. When staining for GluA2, cells were further fixed using chilled methanol at $4^{\circ} \mathrm{C}$ for 10 min before Triton permeabilization.

Image processing and analysis. All images were acquired using a Nikon Eclipse TE2000 inverted fluorescence microscope; cells were examined under a $60 \times$ Plan Apochromatic oil lens. Cells were photographed using a monochrome low-noise cooled CCD camera (SPOT-RT, Diagnostic Instruments) under the control of MetaMorph image-acquisition software (Universal Imaging). Images were processed using Adobe Photoshop to adjust intensity and contrast, and to select regions of interest. All images were obtained in monochrome gray scale and then converted to pseudocolor for presentation.

All data were quantified using MetaMorph analysis software (Universal Imaging). Images were thresholded to distinguish synaptic puncta and dendrites based on protein expression levels. Newly formed synapses located around COS7 cells were identified by examining their colocalization with presynaptic markers: PSD-95 puncta that located on the touch edges of COS7 cell-neuron but without synapsin signals were quantified as newly formed synapses; PICK1 clusters that were not colocalized with synapsin were quantified; and GluA1/2 clusters that were not colocalized with SV2 were quantified. For each quantification, we used more than three independent experimental repeats, and 5-20 neurons were analyzed in each experiment ( $n$ represents experimental repeats). Statistical comparisons were made using SPSS one-way ANOVA analysis, and multiple comparisons were performed by Sidak post hoc tests or independent-samples Kruskal-Wallis test. The bar charts were drawn using SPSS as well.

\section{Results}

PICK1 targets to neurexin-induced synapses after overexpression

Neurexin was reported to induce the formation of postsynaptic specializations that lack AMPA receptors (Graf et al., 2004). This indicates that these newly formed postsynaptic specializations, 
A

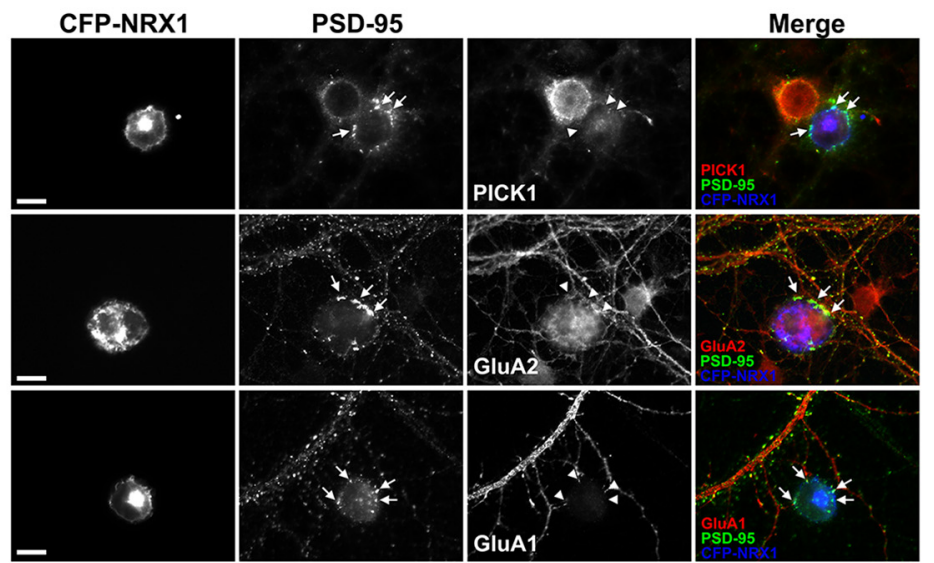

B
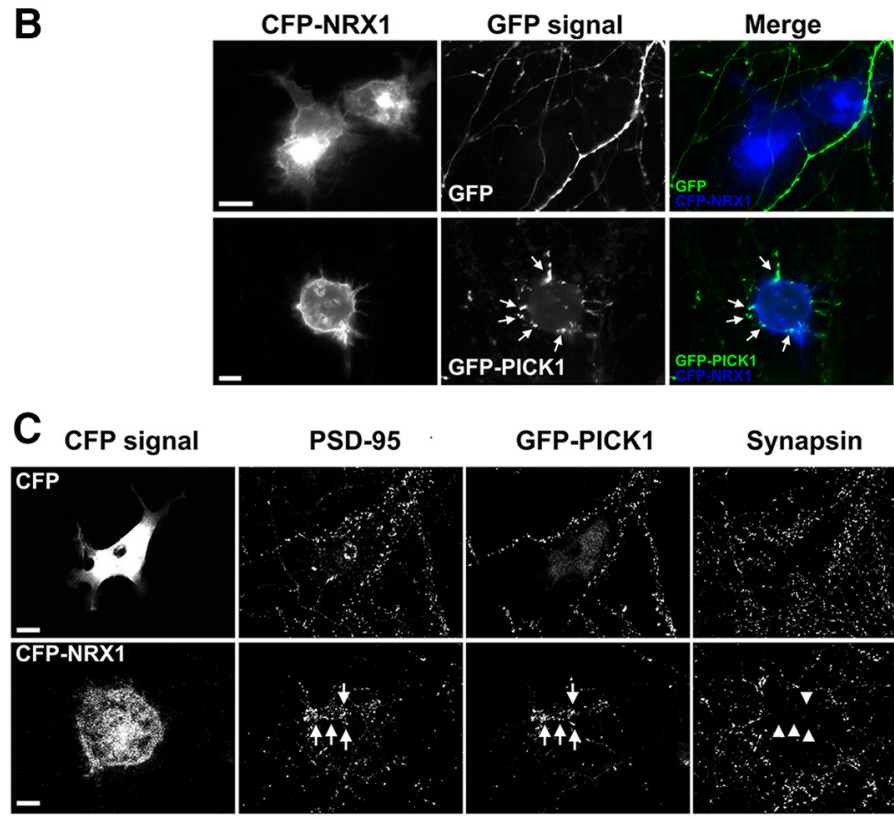

\begin{abstract}
Synapsin
\end{abstract}

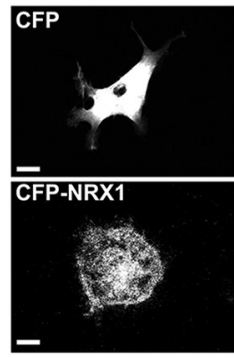

Figure 1. Neurexin induced clustering of overexpressed PICK1 in coculture system. $\boldsymbol{A}$, Neurexin1-induced postsynaptic structures contained no endogenous PICK1, GluA2, or GluA1. Hippocampal neurons-COS7 cell cocultures were stained with antibodies against PSD-95, PICK1, GluA2, or GluA1. Arrows indicate some of the distinct PSD-95 clusters induced by neurexin1 (arrows), and no endogenous PICK1, GluA1, or GluA2 signal was detected on these PSD-95 clusters (arrowheads). Scale bars, $10 \mu \mathrm{m} . \boldsymbol{B}$, Neurexin1-expressing COS7 cells induced GFP-PICK1 clusters (arrows) in hippocampal neurons at contact sites; no clusters were induced in the GFP controls. Scale bars, $10 \mu \mathrm{m}$. C, COS7 cells were expressing CFP or CFP-NRX1 before coculture with GFP-PICK1expressing neurons, as indicated in each row. The cocultures were stained with PSD-95 and synapsin. Successful induction of PSD-95 puncta and GFP-PICK1 puncta by COS7 cells expressing CFP-NRX1 were detected (arrows), but not CFP alone. The lack of synapsin signal on these PSD-95 clusters confirms the identity of new synapses (arrowheads). Scale bars, $10 \mu \mathrm{m}$.

referred to as new synapses hereafter, are silent synapses. Given that the translocation of intracellular AMPA receptors could be modulated by its interacting proteins such as PICK1, we investigated whether AMPA receptors were lacking at these newly formed synapses as a result of the absence of PICK1. To test this hypothesis, we first determined whether endogenous PICK1 was present at newly formed synapses that were induced by neurexin using the coculture system. In the coculture system, the COS7 cells expressing neurexin would induce the formation of postsynaptic specializations on contacting hippocampal neurons. These newly formed synapses are hemi-synapses composed by a pseudo-presynaptic structure on COS7 cells and a postsynaptic specialization on hippocampal neurons. Hippocampal neurons were cocultured with neurexin-expressing (CFP-NRX1) COS7 cells, and then immunostained for PICK1 and PSD-95, a scaffold protein at excitatory synapse. PSD-95 clusters were localized on neuronal dendrites that contacted COS7 cells, indicating a successful induction of new synapses (Fig. 1A). However, no PICK1 clusters were found colocalized with these PSD-95 puncta (Fig. $1 A$ ), indicating the absence of PICK1 at neurexin-induced synapses. Moreover, AMPA receptors were not detected at these synapses by immunostaining for either the GluA2 or GluA1 subunit (Fig. 1A). These results agreed with the previous finding that neurexin-induced synapses lack AMPA receptors (Graf et al., 2004). Furthermore, the results demonstrated that endogenous PICK1 was also absent at the newly induced synapses.

Previously, we demonstrated that homomeric PICK1 was preferentially targeted to synapses (Cao et al., 2007). Because we failed to detect PICK1 at neurexin-induced synapses, we surmised that this was because most of the endogenous PICK1 formed heterodimers with its interacting partner ICA69, and was thus prevented from being recruited to the synapse. To address this hypothesis, we overexpressed PICK1 in hippocampal neurons, which we predicted would exhaust endogenous ICA69 for PICK1 binding and increase homodimeric PICK1 levels. GFP-tagged PICK1 (GFP-PICK1) was introduced into neurons by using Sindbis virus infection, and the neurons were then cocultured with COS7 cells to examine whether PICK1 was localized at the neurexin-induced synapses. Analysis of GFP-PICK1 localization by fluorescent imaging revealed that it clearly formed clusters around neurexin-expressing COS7 cells, indicating that PICK1 was efficiently targeted to the neurexin-induced synapses after overexpression (Fig. 1B). To exclude the possibility that these clusters were generated as a result of the random aggregation of proteins, GFP was overexpressed in neurons as a control instead of GFP-PICK1. No clear GFP clusters were detected around the transfected COS7 cells (Fig. $1 B$ ), suggesting that GFP-PICK1 was clustered specifically. Overall, these results indicate that PICK1 can be readily recruited to neurexin-induced synapses when it is overexpressed and presumably in a homomeric form.

To further confirm that the neurexin-induced PICK1 clusters were localized at newly formed postsynaptic sites, we immunostained the cocultures with antibodies against both the postsynaptic marker PSD-95 and the presynaptic marker synapsin. Because COS7 cells do not express endogenous synapsin, the newly induced synapses should possess PSD-95 but not synapsin. In GFP-PICK1-expressing neurons, we observed that PICK1 clusters were colocalized with PSD-95 clusters at which no synapsin signals were detected (Fig. $1 C$, bottom panels). These results clearly indicate that overexpressed PICK1 was targeted to 
A

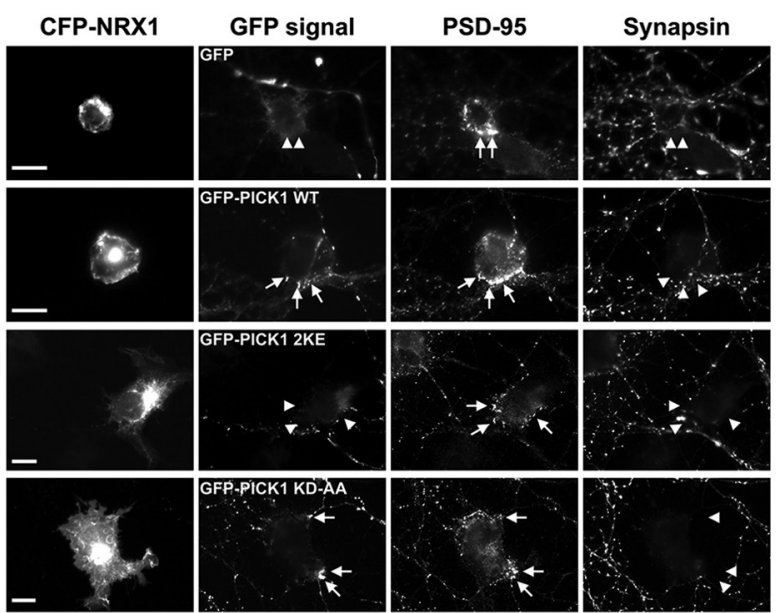

B

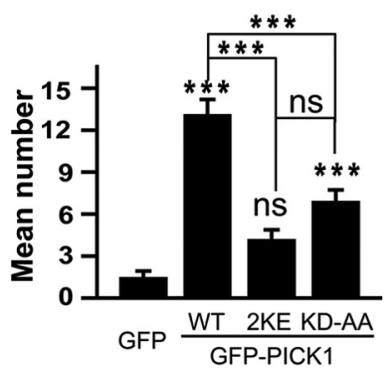

\section{C}

PSD-95 cluster number

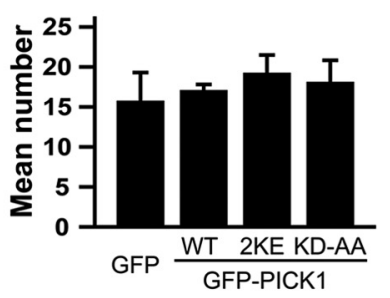

GFP cluster area

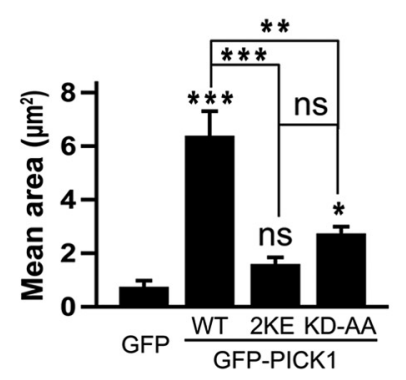

D

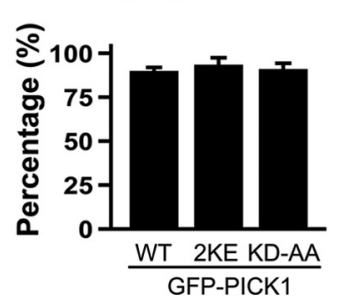

Figure 2. PICK1 clustered at newly induced synapses. A, PSD-95 and synapsin antibodies were used to stain the cocultures. The lack of synapsin on PSD-95 clusters confirms the identity of new synapses (arrowhead in synapsin staining). Neurexin1-induced wild-type PICK1 clusters were colocalized with PSD-95-positive puncta (arrows, second row), whereas no clusters were detected for GFP or the GFP-PICK1 2KE mutant (arrowheads, first and third rows). In neurons infected with the GFP-PICK1 KD-AA virus, PICK1 clusters were colocalized with PSD-95 puncta (arrows, bottom row). Scale bars, $10 \mu \mathrm{m}$. B, Quantification of PICK1 clustering at newly induced synapses. The numbers of induced clusters were (from left to right) $1.5 \pm 0.4,13.2 \pm 1.0$, $4.2 \pm 0.7$, and $6.9 \pm 0.8$; and statistical differences were reported as follows (one-way ANOVA: $\left.F_{(3,48)}=40.53 ; p<0.001\right)$ : Sidak post hoc test, ${ }^{* * *} p<0.001 ; n s p>0.05 ; n=10-15$ experimental repeats. The numbers of induced cluster areas were (from left to right): $0.7 \pm 0.2$, $6.4 \pm 0.9,1.6 \pm 0.2$, and $2.7 \pm 0.3 \mu \mathrm{m}^{2}$. Statistical differences $(p<0.001$, nonparametric Kruskal-Wallis test) are reported as follows: ${ }^{*} p<0.05,{ }^{* *} p<0.01,{ }^{* * *} p<0.001$, nsp $>$ $0.05 ; n=10-15$ experimental repeats. The statistical differences compared with GFP control were indicated just above the bars, and the statistical differences compared with PICK1 WT or mutants were indicated above corresponding connecting lines. Error bars represent the SE. C, Quantification of newly induced PSD-95 clusters. The number of induced PSD-95 clusters were (from left to right) $15.8 \pm 3.5,17.1 \pm 0.7,19.3 \pm 2.2$, and 18.1 \pm 2.7 . One-way ANOVA: $F_{(3,12)}=0.39, p=0.761, n=3-4$ experimental repeats. There was no significant change of PSD-95 cluster numbers among the four experimental groups. Error bars represent the SE. $D$, Quantification of the percentage of synaptic PICK1 clusters, which is the percentage of PICK1 WT and PICK1 mutant clusters colocalized with PSD-95. The percentages were (from left to right) as follows: $89.9 \pm 2.1 \%, 93.4 \pm 4.0 \%$, and $90.9 \pm 3.3 \%$. One-way ANOVA: $F_{(2,9)}=0.36, p=$ $0.710, n=3-4$ experimental repeats. There was no significant difference of synaptic PICK1 clusters among the three experimental groups. Error bars represent the SE.

A

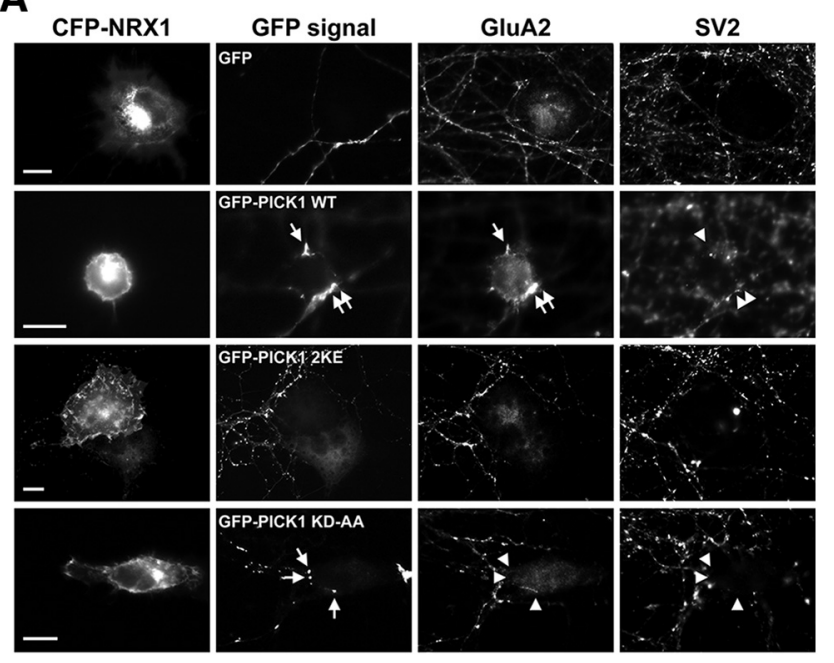

B

GluA2 cluster number

GluA2 cluster area
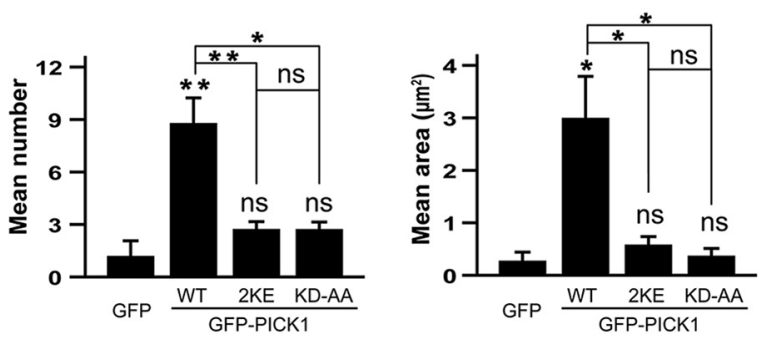

Figure 3. GluA2 clusters were induced in the presence of PICK1. A, GluA2 and presynaptic marker SV2 antibodies were used to stain the cocultures. GluA2 clusters colocalized with PICK1 WT, but not with GFP or PICK1 mutants. A few distinct PICK1 and GluA2 clusters were induced in the cocultures (arrows). The GluA2 signal was absent on the PICK1 KD-AA clusters (arrowheads). The lack of SV2 signal on PICK1 clusters confirms the identity of new synapses (arrowheads). Scale bars, $10 \mu \mathrm{m} . \boldsymbol{B}$, Quantification of the numbers and areas of induced GluA2 clusters at new synapses. The numbers of induced GluA2 clusters were (from left to right) $1.2 \pm 0.9,8.8 \pm 1.4$, $2.7 \pm 0.4$, and $2.7 \pm 0.4$; and the areas of induced clusters were (from left to right) $0.3 \pm 0.2$, $3.0 \pm 0.8,0.6 \pm 0.2$, and $0.4 \pm 0.1 \mu \mathrm{m}^{2}$. Statistical differences (one-way ANOVA: $F_{(3,17)}=$ 11.07 and $p<0.01$ for induced number; $F_{(3,17)}=6.32$ and $p<0.01$ for induced area). Sidak post hoc test: ${ }^{*} p<0.05,{ }^{* *} p<0.01$, ns $p>0.05 ; n=3-6$ experimental repeats. The statistical differences compared with GFP control were indicated just above the bars, and the statistical differences compared with PICK1 WTs or mutants were indicated above the corresponding connecting lines. Error bars represent the SE.

newly formed synapses. In addition, we could not observe any new synapse formation or PICK1 cluster induction when COS7 cells were expressing CFP (Fig. 1C, top panels). GFP-PICK1 clusters could be induced in newly formed synapses only when COS7 cells expressed CFP-neurexin $1 \beta$.

\section{PICK1 clustering at new synapses depends on its}

lipid-binding ability

The synaptic targeting of PICK1 is mediated by the binding of its BAR (Bin/Amphiphysin/Rvs) domain to negatively charged lipids (Jin et al., 2006), and a double glutamate substitution in the BAR domain [K266E/K268E (2KE)] eliminates the lipid-binding and synaptic-targeting abilities of PICK1 (Jin et al., 2006). To test whether the clustering of PICK1 at newly induced synapses depends on the ability of PICK1 to bind lipids, we introduced the same BAR domain mutant (GFP-PICK1 2KE) into hippocampal neurons by using viral infection. In the cocultures prepared using these neurons, new synapses were induced successfully, as indicated by positive PSD-95 staining and negative synapsin staining 

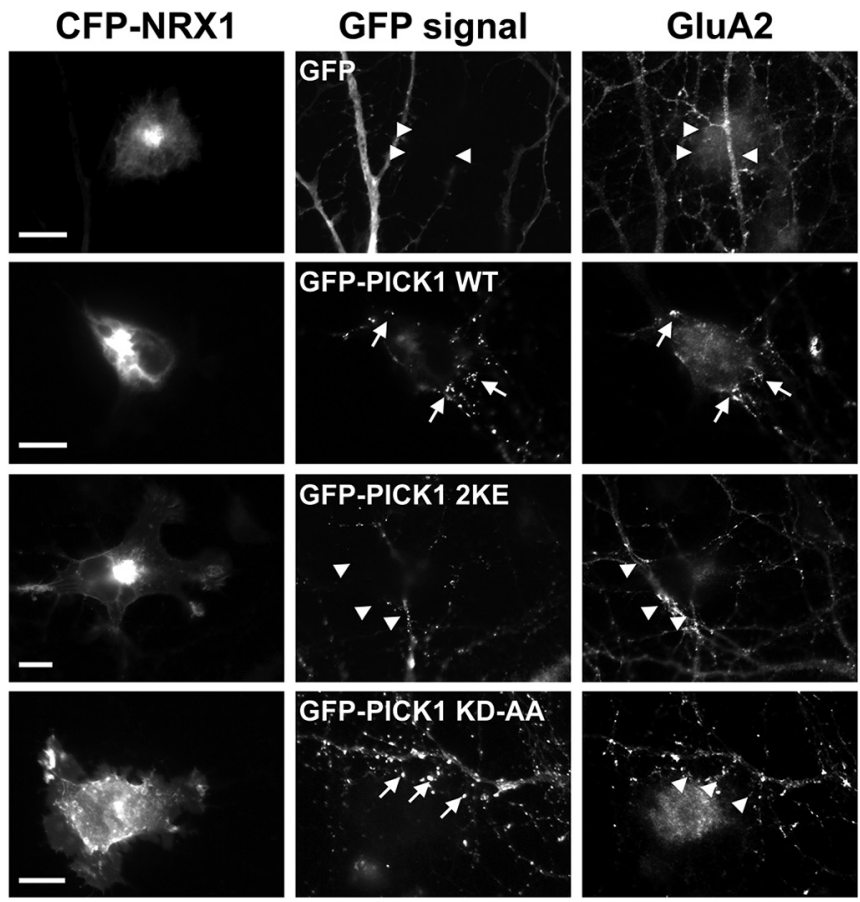

Figure 4. GluA2 clusters induced by PICK1 are localized at new synapses. GluA2 clusters were colocalized with PICK1 WT and PSD-95. No GluA2 puncta were detected at induced PSD-95 puncta in neurons infected with GFP, GFP-PICK1 2KE, or GFP-PICK1 KD-AA viruses. Arrows indicate some of the distinct PICK1 and PSD-95 clusters induced by neurexin1, and arrowheads indicate the PSD-95 clusters that lack GluA2 or PICK1 signals. Scale bars, $10 \mu \mathrm{m}$.

(Fig. 2A, GFP-PICK1 2KE); however, the mutant form of PICK1 was absent at these induced synaptic sites (Fig. 2A, GFP-PICK1 2KE). Quantification of the induced PICK1 WT or 2KE mutant clusters also showed significant differences between PICK1 WT and GFP, or PICK1 WT and PICK1 2KE mutant both in induced cluster number and induced cluster area (Fig. 2B). However, the PICK1 2KE mutant showed no difference from GFP control in either measure (Fig. 2B). This result indicates that the lipidbinding property of PICK1 is required for PICK1 targeting to neurexin-induced synapses.

The K27A/D28A (KD-AA) mutation in the PDZ [PSD-95/ Discs large (Dlg)/zona occludens-1 (ZO-1)] domain of PICK1 abolishes its capability to interact with PDZ domain-binding proteins such as GluA2 (Xia et al., 1999). This mutant exhibited reduced synaptic targeting compared with wild-type (WT) PICK1, but still was targeted to synapses more efficiently than the 2KE mutant (Jin et al., 2006). We introduced the mutant GFPPICK1 KD-AA into neurons and found that the mutant protein could be clustered at induced synapses in the coculture system (Fig. 2A, GFP-PICK1 KD-AA). Statistical analysis of the induced PICK1 clusters also showed significant differences between PICK1 KD-AA mutant and GFP or PICK1 KD-AA and PICK1 WT (Fig. 2B) both in induced cluster number and induced cluster area, indicating a moderate synaptic targeting ability of PICK1 KD-AA. This result indicates that the BAR domain of PICK1 plays a more dominant role in targeting PICK1 to neurexininduced synapses than the PDZ domain.

To exclude the possibility that different PICK1 mutants could change the number of neurexin-induced synapses, we quantified the number of induced PSD-95 clusters. Statistical comparison showed that the induced PSD-95 was similar among all four groups (Fig. 2C). We also quantified the percentage of PICK1 clusters that were colocalized with PSD-95. Results showed that
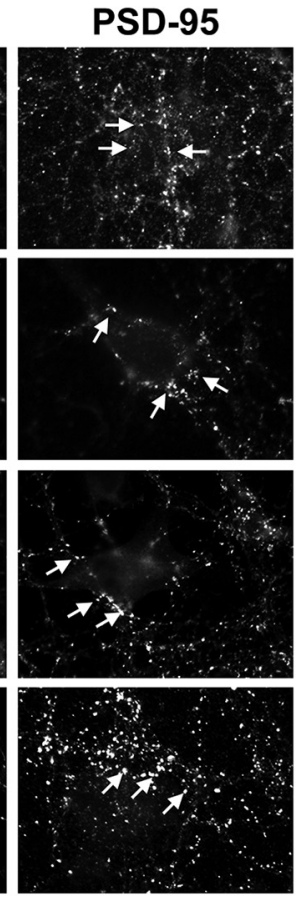

most ( $\sim 90 \%)$ of the induced PICK1 WT, $2 \mathrm{KE}$, or KD-AA mutant clusters were colocalized with PSD-95 (Fig. 2D). Together, these data indicate that PICK1 forms clusters at neurexin-induced new synapses and that this clustering depends mainly on the lipid-binding capability of the BAR domain of PICK1.

\section{PICK1 promotes GluA2 trafficking to newly induced synapses}

After confirming that PICK1 could be recruited to neurexin-induced synapses, we examined whether this synaptic enrichment of PICK1 affected the localization of AMPA receptors. To investigate the role of PICK1 in AMPA receptor recruitment at newly formed synapses, we again used the coculture system expressing GFPPICK1 or GFP in hippocampal neurons. The absence of the presynaptic marker SV2 was used to distinguish the neurexininduced new synapses from pre-existing synapses. The immunofluorescent signal of the AMPA receptor subunit GluA2 in neurons expressing GFP-PICK1 but not GFP was detected at new synapses around COS7 cells (Fig. 3A). No GluA2 signal was observed in neurons expressing the PICK1 2KE mutant (Fig. 3A, GFP-PICK1 $2 \mathrm{KE}$ ). To examine whether the synaptic incorporation of AMPA receptors depends on the direct interaction between PICK1 and GluA2, we infected neurons with the GluA2 binding-deficient GFP-PICK1 KD-AA virus and then cocultured these neurons with COS7 cells. We observed a largely diminished GluA2 signal on induced PICK1 KD-AA clusters compared with wild-type PICK1 (Fig. 3A, GFP-PICK1 KD-AA). Statistical comparison of the induced GluA2 clusters showed that wild-type PICK1 induced the largest number of GluA2 clusters and also the largest GluA2 clusters. The PICK1 2KE mutant, which can bind GluA2, recruited GluA2 to synapses to a much lower degree than wildtype PICK1 did, and the PICK1 KD-AA mutant exhibited a low GluA2 recruitment efficiency that was similar to that of the PICK1 2KE mutant (Fig. 3B). The results indicate that AMPA receptors were recruited to newly formed synapses in the presence of PICK1 and that this synaptic recruitment of AMPA receptors was directly mediated by PICK1 and depended on PICK1-GluA2 complex formation.

To verify that the induced GluA2 puncta were indeed localized at synapses, we stained the cells with both GluA2 and PSD-95 antibodies. When wild-type PICK1 was introduced into neurons, GluA2 was found colocalized with induced PSD-95 and PICK1 clusters (Fig. 4, GFP-PICK1 WT). By contrast, in neurons expressing the PICK1 2KE mutant, the newly induced synapses lacked PICK1 2KE, and, consequently, GluA2 puncta were not detected at either of these sites (Fig. 4, GFP-PICK1 2KE). The PICK1 KD-AA mutant formed clusters at the induced PSD-95 puncta, but no GluA2 signal was detected at these sites because of the lack of PICK1-GluA2 interaction (Fig. 4, GFP-PICK1 KDAA). Combined with our other results, these findings indicate that the recruitment of AMPA receptors to new synapses depends on both the lipid-binding ability of PICK1 and the PICK1-GluA2 interaction. 
PICK1 promotes GluA1 trafficking into newly induced synapses

PICK1 binds to GluA2, 3, and 4c subunits, but not to GluA1 directly (Xia et al., 1999). However, $>90 \%$ of the AMPA receptors are composed of GluA1/2 or GluA2/3 complexes in neurons (Wenthold et al., 1996). Therefore, GluA1 may also be incorporated at synapses in GluA1/2 complexes as a consequence of the interaction of PICK1 with GluA2. We tested this hypothesis by staining the cocultures with a GluA1specific antibody. Imaging and quantitative data showed a similar expression pattern of GluA1 signal on new synapses: GluA1 clusters were found colocalized with wild-type PICK1, but neither the PICK1 2KE mutant nor the PICK1 KD-AA mutant could recruit GluA1 to newly formed synapses (Fig. 5). These results indicate that AMPA receptor complexes containing both GluA1 and GluA2 require PICK1 for its translocation to newly induced synapses.

\section{AMPA receptors traffic independently} of PICK1-neuroligin interaction

In the coculture system, neuroligin 1 and PSD-95 were previously reported to jointly drive the recruitment of NMDARs to HEK293T cell membranes that were in contact with axons (Fu et al., 2003). PICK1 has been shown to interact with the $\mathrm{C}$ terminus of neuroligin1, as described previously (Meyer et al., 2004). The interaction between neuroligin 1 and PICK1 could also potentially drive the recruitment of AMPA receptors to the contact sites in cocultures. However, there are also data showing that neuroligin 1 did not form complexes with AMPA receptor subunits GluA2/3 (Budreck et al., 2013). To further verify this, we attempted to test whether neuroligin1 contributes to the formation of the PICK1-AMPA receptor complex, using heterologous HEK293T cells transfected with CFP-PICK1 and GluA2, with or without YFP-NL1. PICK1 or GluA2 expressed alone showed a diffuse distribution in the cytoplasm other than forming a few puncta, and the coexpression of PICK1 and GluA2 in HEK293T cells exhibited a number of discrete PICK1-GluA2 coclusters in the cytoplasm (Fig. $6 A$ ). Further experiments showed that the overexpression of YFP-NL1 neither increased the formation of these coclusters nor disrupted them (Fig. 6A), indicating that YFP-NL1 did not directly affect the assembly of the PICK1-AMPA receptor complex.

Neuroligins induce presynaptic specialization in contacting axons in an HEK293T-hippocampal neuron coculture system (Scheiffele et al., 2000; Fig. 6B). To test whether neuroligin1 is responsible for recruiting the PICK1-GluA2 complex to synapses, we designed a similar coculture system: HEK293T cells cocultured with hippocampal neurons were transfected with

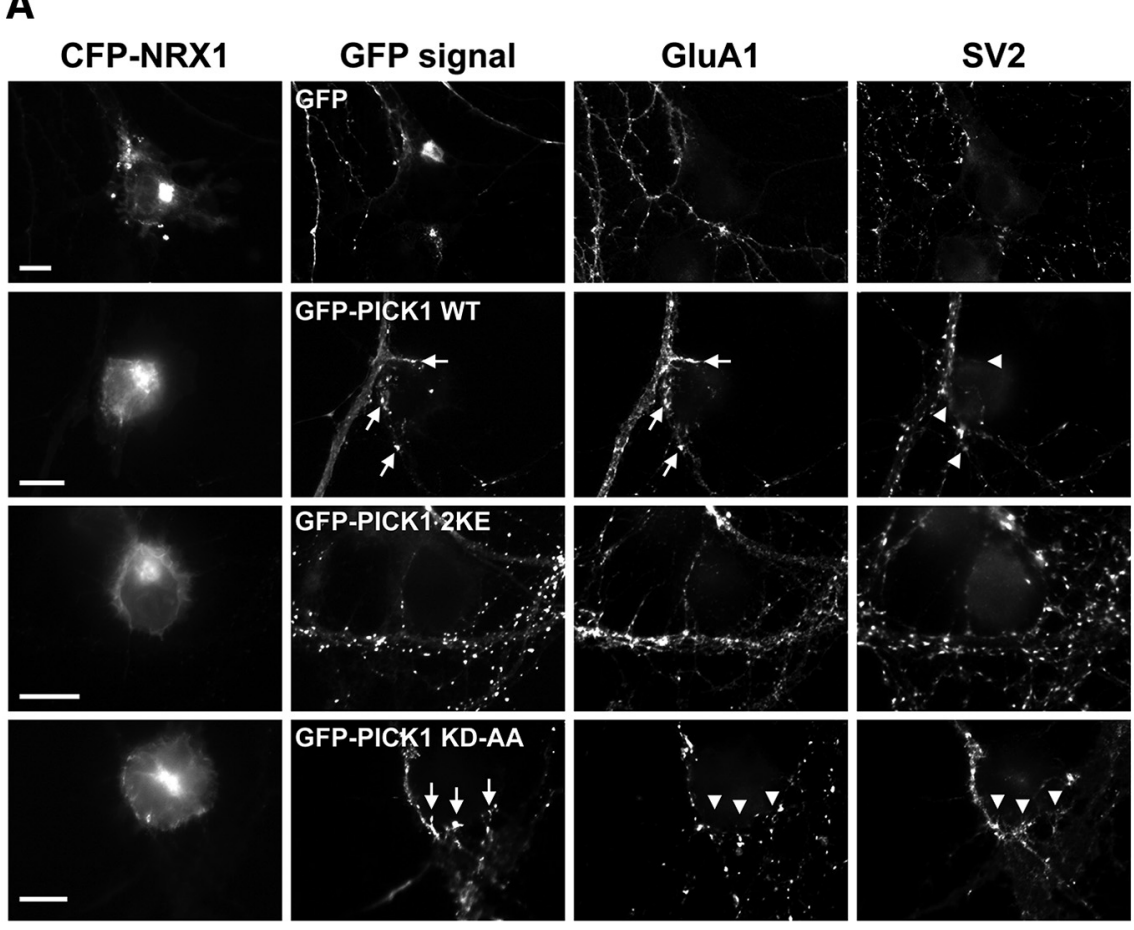

B GluA1 cluster number

\section{GluA1 cluster Area}

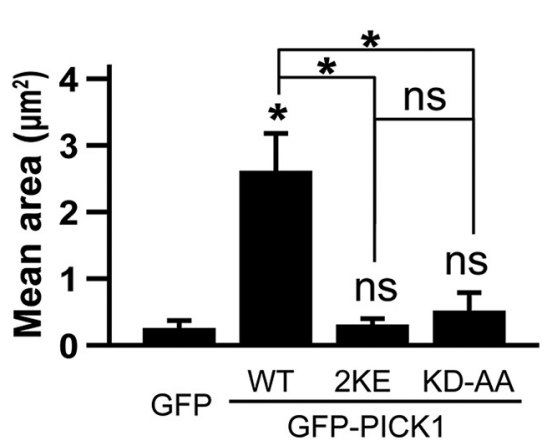

Figure 5. GluA1 clusters were induced by PICK1 at new synapses. $A$, GluA1 clusters colocalized with PICK1 WTs, but not with GFP or PICK1 mutants. A few distinct PICK1 and GluA1 clusters were induced in the cocultures (arrows). A GluA1 signal was absent on PICK1 KD-AA clusters (arrowheads). The lack of SV2 signal on the induced PICK1 clusters confirms the identity of new synapses (arrowheads). Scale bars, $10 \mu \mathrm{m}$. B, Quantification of the numbers and areas of induced GluA1 clusters at new synapses. The (from left to right) $1.3 \pm 0.6,11.1 \pm 2.4,2.4 \pm 0.7$, and $1.8 \pm 0.8$; the areas of induced $F_{(3,12)}=9.39$ and $p<0.01$ for induced cluster number; $F_{(3,12)}=9.77$ and $p<0.01$ for induced cluster area). Sidak post hoc test: (1) 05 , nsp $>0.05 ; n=3-4$ experimental repeats. The statistical differences compared with GFP control were indicated just above the bars, and the statistical differences compared with PICK1 WT or mutants were indicated above the corresponding connecting lines. Error bars represent the SE.

YFP-NL1 and GluA2 in the presence or absence of PICK1. In these cocultures, image analysis revealed that HEK293T cells were doubly transfected with YFP-NL1 and GluA2-induced synapses, as shown by the immunofluorescent signal of SV2, but that GluA2 was not recruited to these contact sites between neurons and HEK293T cells (Fig. 6C, top panels). To further assess the function of PICK1, we introduced PICK1 into the coculture system by transfecting HEK293T cells with YFP-NL1, GluA2, and PICK1. PICK1 and GluA2 formed numerous coclusters, as shown before (Fig. $6 A$ ), but these coclusters were distributed in the cytoplasm and were not detected at the induced presynaptic sites using SV2 as a marker (Fig. 6C, bottom panels). This result 
A

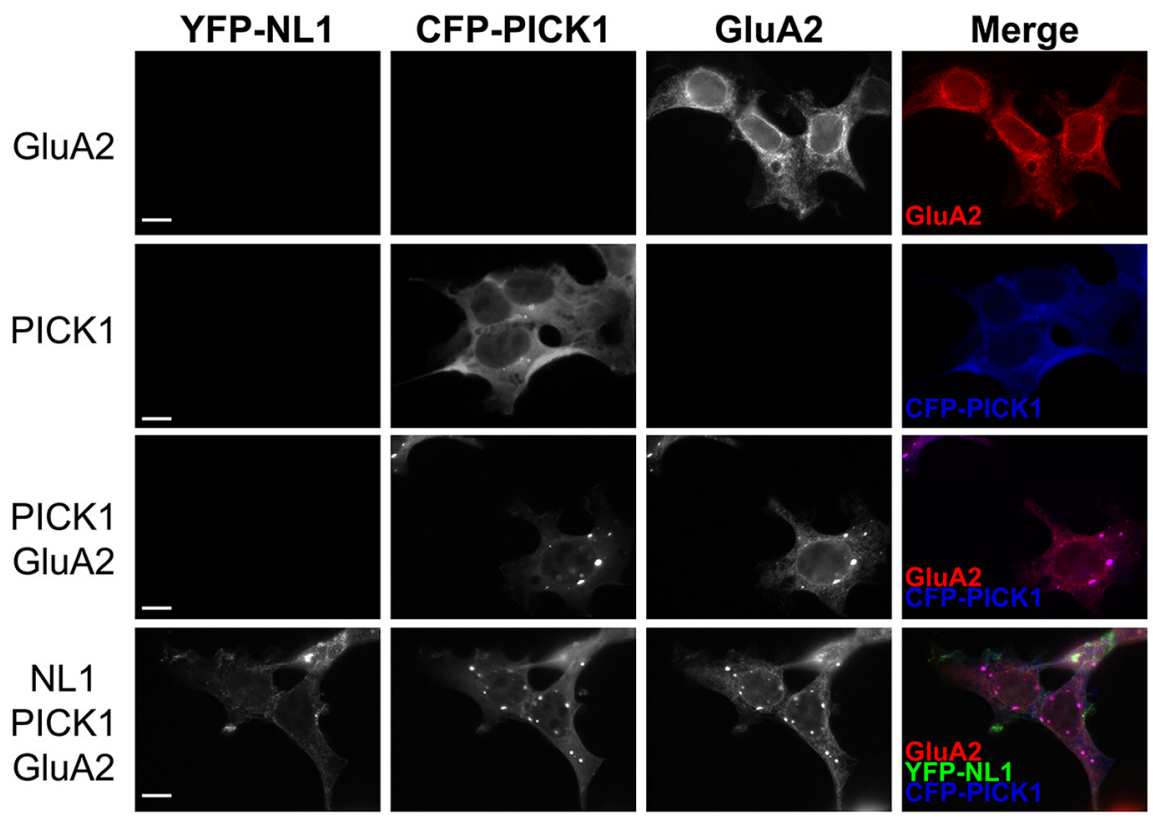

B
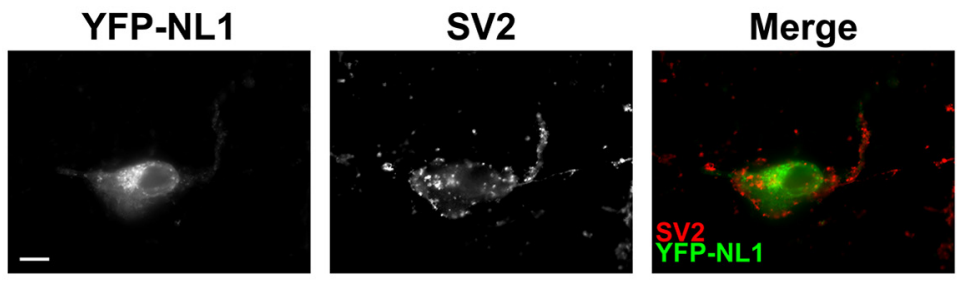

C

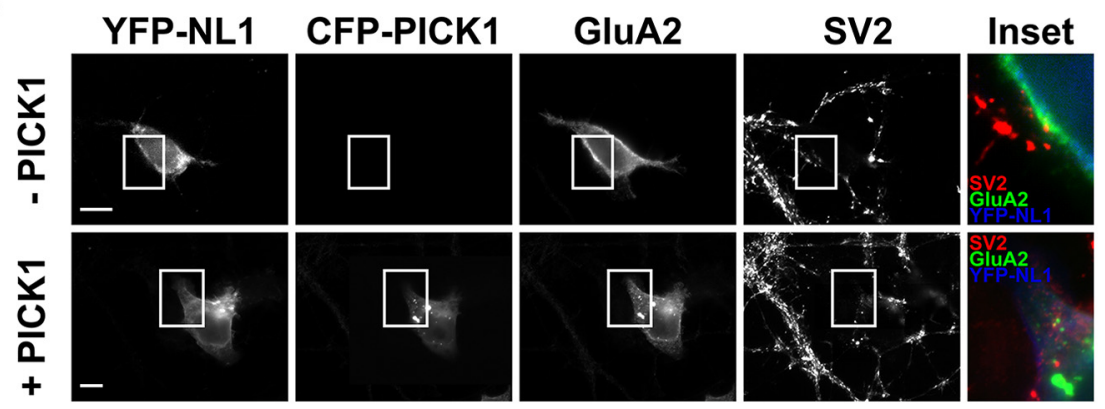

Figure 6. PICK1 and GluA2 targeted to synapses independent of neuroligin1-PICK1 interaction. $\boldsymbol{A}$, HEK293T cells were transfected with CFP-PICK1, GluA2, and YFP-NL1 constructs in various combinations, and the cells were then stained for GluA2. PICK1 and GluA2 formed numerous coclusters in the cytoplasm, and YFP-NL1 neither changed the clustering pattern of PICK1-GluA2 nor existed in the coclusters. Scale bars, $10 \mu \mathrm{m}$. B, Neuroligin1-induced presynaptic structures at neuron-COS7 cell contact sites. Scale bars, $10 \mu \mathrm{m}$. C, GluA2 did not translocate to the contact sites where neuroligin1-induced presynaptic structures. Top panels show that when GluA2 was coexpressed with YFP-NL1, no local concentration of GluA2 was induced at the cellular contact sites. Bottom panels show that when PICK1 was coexpressed with GluA2 and YFP-NL1, no GluA2-PICK1 coclusters were colocalized with the induced presynaptic puncta stained by the SV2 antibody. The panels on the right (Inset) show enlarged images of neuronHEK293T cell contact regions. Scale bars, $10 \mu \mathrm{m}$.

indicates that the PICK1-GluA2 complex was not influenced by the presence of neuroligin1, and that the recruitment of AMPA receptors was not directly mediated by the formation of AMPA receptor-PICK1-neuroligin complexes. Additional cytoplasmic components are probably required to recruit PICK1 and AMPA receptors to the synapses in neurons.

\section{ICA69 regulates PICK1-mediated synapse maturation}

Most of the PICK1 in cells forms heterodimers with its interacting partner ICA69 (Cao et al., 2007), and we found that enrich- ment of PICK1 could increase its ability in targeting to neurexin-induced synapses. This raised the intriguing possibility that ICA69 determines the state of synapse maturation by regulating PICK1 homodimer formation and synaptic targeting of PICK1 and GluA2. Supporting this hypothesis, in hippocampal neurons that coexpressed ICA69 and PICK1, ICA69 showed the ability to restrict PICK1 localization to dendritic shafts and prevent the synaptic targeting of PICK1 (Cao et al., 2007; Fig. 7A).

Because we found that the synaptic targeting of PICK1 is dependent on ICA69, we sought to determine the role of ICA69 in AMPA receptor recruitment to newly induced synapses in the coculture system. Neurons transfected with PICK1 and ICA69 were cocultured with neurexinexpressing COS7 cells, and stained for PICK1, ICA69, and SV2. Only when PICK1 was transfected into neurons were synapses containing PICK1 detected around the COS7 cells, and the lack of SV2 signals at these PICK1 puncta indicated that these were newly induced synapses (Fig. 7B, top panels). By contrast, when ICA69 was expressed together with PICK1, PICK1 was constrained in small dendritic clusters together with ICA69, and no PICK1 clusters could be observed at the contact sites between neurons and the COS7 cells (Fig. 7B, bottom panels). To gain further insight into the functionality of the newly induced synapses, we also investigated the subcellular localization of GluA1 and GluA2 in these cocultures. GluA1 and GluA2 were successfully recruited to newly formed synapses when PICK1 alone was overexpressed with them. However, both GluA1 and GluA2 were absent at the newly induced synapses when ICA69 was coexpressed with PICK1 in the neurons (Fig. $7 C, D$ ). These results indicate that ICA69 functions as a key regulator of synapse maturation by retaining the PICK1-AMPA receptor complex at dendrites and preventing them from targeting to synapses.

\section{Discussion}

Neurons possess both mature and immature synapses at the same developmental stage, which makes investigating the maturation of single synapses challenging. Neurexin-induced synapses in the coculture system used here are postsynaptically silent because of the absence of AMPA receptors (Graf et al., 2004). Using the coculture system, we can readily distinguish the newly formed, immature synapses from previously formed synapses. This provided us with a model suitable for studying the effect of PICK1 on the synaptic recruitment of AMPA receptors. By enriching PICK1 in neurons, we found that PICK1 was able to cluster at the postsynapses induced by neurexin. The AMPA 
A

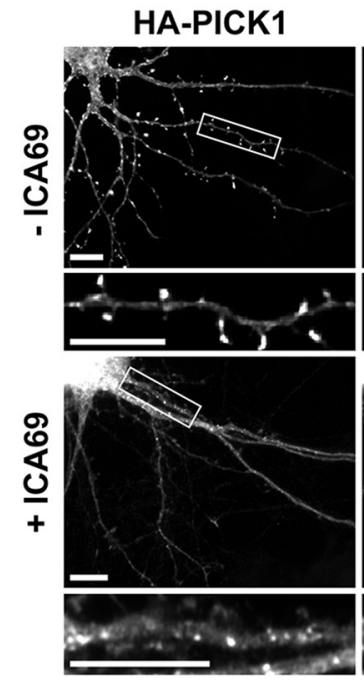

myc-ICA69
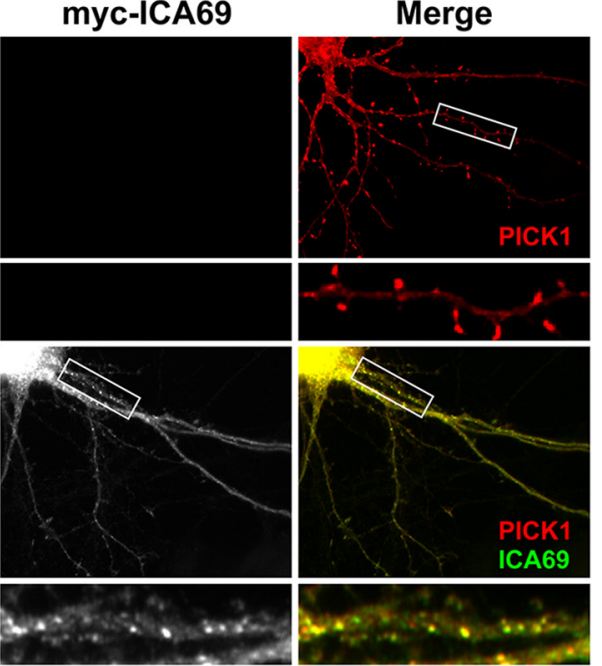

B
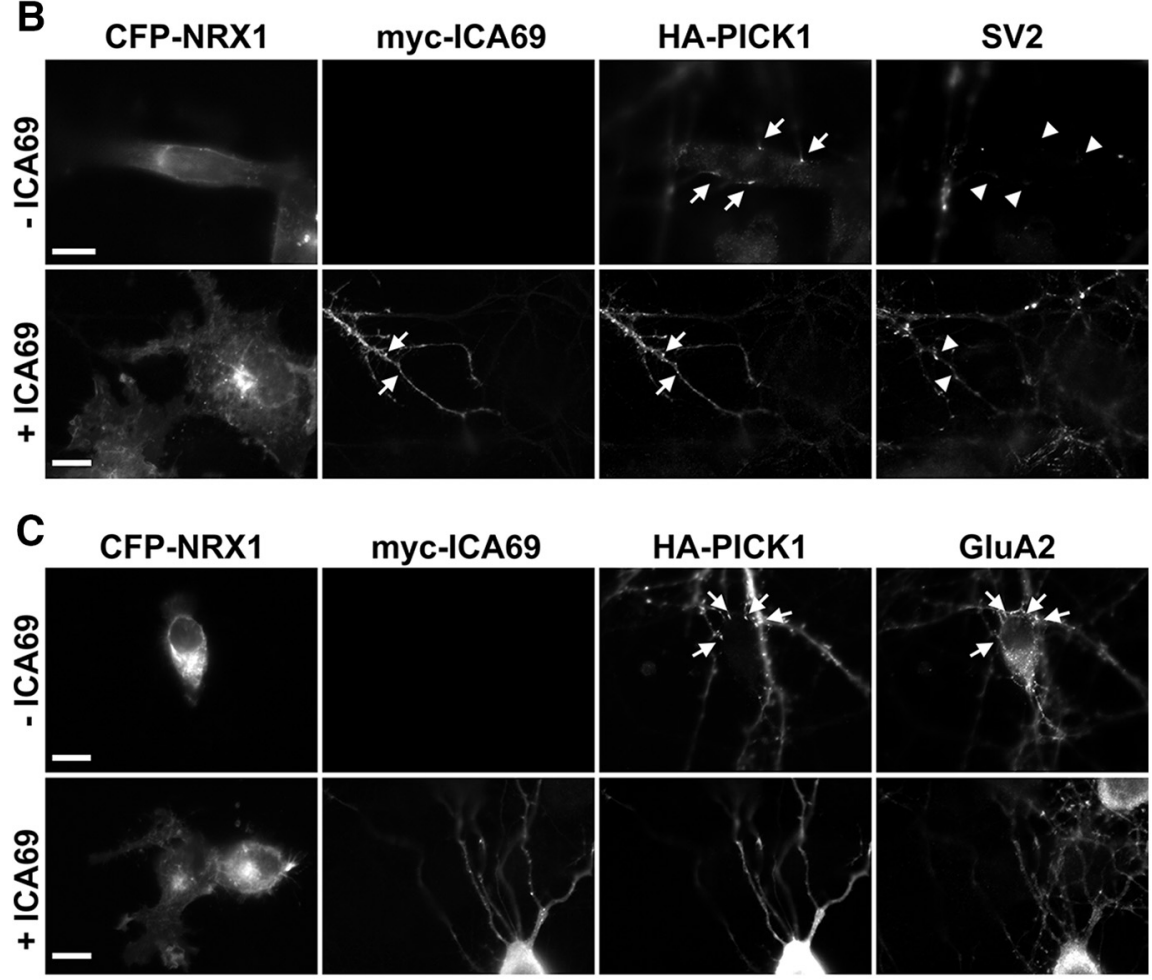

\section{CFP-NRX1}

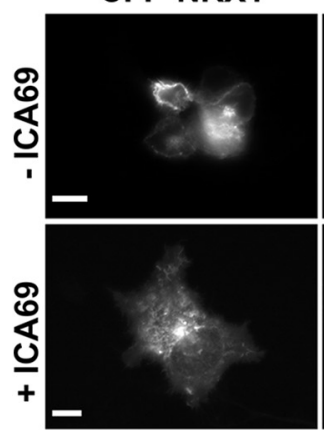

myc-ICA69

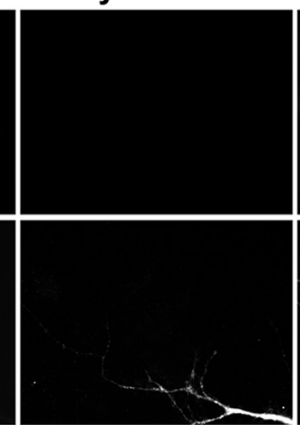

HA-PICK1

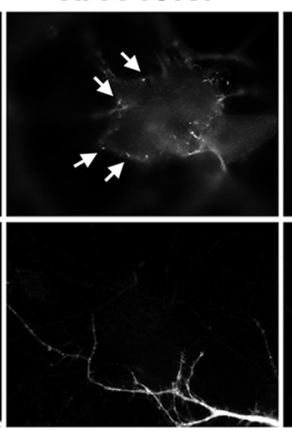

GluA1

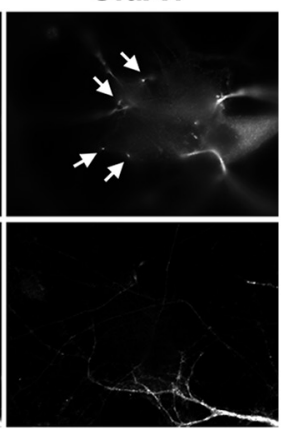

Figure 7. ICA69 negatively regulated PICK1-mediated synaptic targeting of GluA2. A, Hippocampal neurons were transfected with PICK alone or with PICK1 and ICA69. In the absence of ICA69, PICK1 was mostly concentrated at synapses, whereas in the presence of ICA69, PICK1 appeared mainly on dendritic puncta together with ICA69. Scale bars, $10 \mu \mathrm{m}$. $\boldsymbol{B}$, Cocultures were prepared using neurons that were previously transfected with PICK1 or PICK1 together with ICA69, and the cocultures were then receptor subunit GluA2 was also detected at these PICK1-enriched synapses. Similarly, GluA1 was also recruited to new synapses by PICK1, presumably via its association with GluA2. To confirm that the synaptic recruitment of AMPA receptors was mediated by means of PICK1GluA2 interaction, we introduced a PICK1 PDZ domain mutant lacking the ability to bind GluA2 (Xia et al., 1999). We observed no GluA2 at newly formed synapses when the interaction between GluA2 and PICK1 was abolished. These findings provide the first evidence demonstrating the role of PICK1 as a direct regulator of AMPA receptor targeting during synapse maturation.

In addition to mediating activitydependent AMPA receptor internalization (Xia et al., 2000; Perez et al., 2001; Steinberg et al., 2006), PICK1 is also suggested to regulate the synaptic or surface delivery of AMPA receptors (Jin et al., 2006; Sossa et al., 2006; Cao et al., 2007; Terashima et al., 2008; Clem et al., 2010; Lu et al., 2014). Whereas AMPA receptors are likely trafficked between an extrasynaptic pool and the synaptic membrane, our study shows that PICK1 could recruit AMPA receptors to synapses by forming a PICK1-AMPA receptor complex. This PICK1-mediated AMPA receptor recruitment may function as a general mechanism of synapse maturation and may not be restricted to neurexin-induced synapses. This dual role of PICK1 in both synaptic delivery and endocytosis of AMPA receptors gives a hint that PICK1 not only functions during synaptic plasticity after construction of neuronal circuits, but may also play a role in activity-dependent synaptic maintenance and elimination, which are critical for synaptic wiring.

Because endogenous PICK1 did not target the synapse as robustly as the overexpressed PICK1 did, we also searched for a potential mechanism that affects the

$\leftarrow$

stained for PICK1, ICA69, and SV2. In the absence of ICA69, PICK1 clusters were successfully induced at neuron-c0S7 cell contact sites (arrows). The absence of an SV2 signal on induced PICK1 clusters confirms the identity of new synapses (arrowheads). When ICA69 was overexpressed, PICK1 clusters were not detected on the contact sites, and PICK1-ICA69 coclusters were detected along dendrites (arrows). Scale bars, $10 \mu \mathrm{m}$. C, Cocultures were stained for PICK1, GluA2, and ICA69. In the absence of ICA69, GluA2 was successfully clustered together with PICK1 (arrows), but when ICA69 was overexpressed, GluA2 and PICK1 clusters were not detected. Scale bars, 10 $\mu \mathrm{m}$. D, Cocultures were stained for PICK1, ICA69, and GluA1. In the absence of ICA69, GluA1 was coclustered with PICK1 (arrows), but when ICA69 was overexpressed, GluA1 and PICK1 clusters were not detected. Scale bars, $10 \mu \mathrm{m}$. 
synaptic enrichment of PICK1. Neuroligin was found to bind to the PDZ domain of PICK1 (Meyer et al., 2004), and the use of the coculture system in a previous study (Fu et al., 2003) demonstrated that the interaction between neuroligin and PSD-95 mediates the targeting of PSD-95-NMDAR complexes to the heterologous cell membrane. These findings raised the possibilities that neuroligin could directly bind to PICK1 and then recruit the PICK1-AMPA receptor complex to synapses in a mechanism similar to the way in which PSD-95 recruits NMDARs to synapses. Our data, however, do not support this model, as neuroligin did not associate directly with the PICK1-AMPA receptor complex. This difference could be explained by the disparity in the domains presented in PICK1 and PSD-95. PSD-95 possesses several PDZ domains, by means of which a single molecule of PSD-95 can concurrently interact with both neuroligin and NMDAR (Kornau et al., 1995; Irie et al., 1997), whereas PICK1 contains only a single PDZ domain, which limits the selection of binding partners for PICK1. Whether PICK1 dimerization through its BAR domain could fulfill the binding capability of PICK1 with NMDAR and neuroligin simultaneously remains unclear, and the functional role of the neuroligin-PICK1 interaction still warrants further exploration. A recent study (Mondin et al., 2011) showed that the aggregation of neurexin-neuroligin complexes by antibodies could quickly (in 30-60 min) immobilize surface AMPA receptors in a PSD-95-dependent manner. Transmembrane AMPA regulatory proteins (TARPs) were proposed as the linker between PSD-95 and AMPA receptors, but no direct evidence shows the involvement of TARPs. Whether PICK1 is involved in this early stage of AMPA receptor immobilization remains to be tested.

ICA69 interacts with PICK1 by forming a heteromeric BAR domain complex with PICK1 and restricts the synaptic targeting of PICK1 and AMPA receptors (Cao et al., 2007). In this study, overexpressing ICA69 prevented the targeting of both PICK1 and AMPA receptors to neurexin-induced synapses, which demonstrates a regulatory role of ICA69 in synapse maturation. ICA69 could serve as a sensor of external stimuli: ICA69 exists in a preformed complex with PICK1 and GluA2, and maintains this protein complex on dendritic shafts (Cao et al., 2007). It is possible that when synapse maturation is initiated, PICK1 could dissociate from ICA69-PICK1 heteromeric BAR domain complexes and form PICK1-PICK1 homomeric BAR domain complexes. These PICK1 homomeric complexes could be targeted to synapses and subsequently recruit GluA2 to synapses. Further studies are needed to elucidate what might trigger the switch from the ICA69-PICK1 heteromeric complex to the PICK1-PICK1 homomeric complex.

\section{References}

Arking DE, Cutler DJ, Brune CW, Teslovich TM, West K, Ikeda M, Rea A, Guy M, Lin S, Cook EH, Chakravarti A (2008) A common genetic variant in the neurexin superfamily member CNTNAP2 increases familial risk of autism. Am J Hum Genet 82:160-164. CrossRef Medline

Baudouin SJ, Gaudias J, Gerharz S, Hatstatt L, Zhou K, Punnakkal P, Tanaka KF, Spooren W, Hen R, De Zeeuw CI, Vogt K, Scheiffele P (2012) Shared synaptic pathophysiology in syndromic and nonsyndromic rodent models of autism. Science 338:128-132. CrossRef Medline

Blundell J, Blaiss CA, Etherton MR, Espinosa F, Tabuchi K, Walz C, Bolliger MF, Südhof TC, Powell CM (2010) Neuroligin-1 deletion results in impaired spatial memory and increased repetitive behavior. J Neurosci 30: 2115-2129. CrossRef Medline

Budreck EC, Kwon OB, Jung JH, Baudouin S, Thommen A, Kim HS, Fukazawa Y, Harada H, Tabuchi K, Shigemoto R, Scheiffele P, Kim JH (2013) Neuroligin-1 controls synaptic abundance of NMDA-type glutamate re- ceptors through extracellular coupling. Proc Natl Acad Sci U S A 110: 725-730. CrossRef Medline

Cao M, Xu J, Shen C, Kam C, Huganir RL, Xia J (2007) PICK1-ICA69 heteromeric BAR domain complex regulates synaptic targeting and surface expression of AMPA receptors. J Neurosci 27:12945-12956. CrossRef Medline

Chubykin AA, Atasoy D, Etherton MR, Brose N, Kavalali ET, Gibson JR, Südhof TC (2007) Activity-dependent validation of excitatory versus inhibitory synapses by neuroligin-1 versus neuroligin-2. Neuron 54:919931. CrossRef Medline

Chung HJ, Xia J, Scannevin RH, Zhang X, Huganir RL (2000) Phosphorylation of the AMPA receptor subunit GluR2 differentially regulates its interaction with PDZ domain-containing proteins. J Neurosci 20:72587267. Medline

Clem RL, Anggono V, Huganir RL (2010) PICK1 regulates incorporation of calcium-permeable AMPA receptors during cortical synaptic strengthening. J Neurosci 30:6360-6366. CrossRef Medline

Dev KK, Nishimune A, Henley JM, Nakanishi S (1999) The protein kinase C alpha binding protein PICK1 interacts with short but not long form alternative splice variants of AMPA receptor subunits. Neuropharmacology 38:635-644. CrossRef Medline

Etherton M, Földy C, Sharma M, Tabuchi K, Liu X, Shamloo M, Malenka RC, Südhof TC (2011) Autism-linked neuroligin-3 R451C mutation differentially alters hippocampal and cortical synaptic function. Proc Natl Acad Sci U S A 108:13764-13769. CrossRef Medline

Feng J, Schroer R, Yan J, Song W, Yang C, Bockholt A, Cook EH Jr, Skinner C, Schwartz CE, Sommer SS (2006) High frequency of neurexin 1beta signal peptide structural variants in patients with autism. Neurosci Lett 409: 10-13. CrossRef Medline

Fu Z, Washbourne P, Ortinski P, Vicini S (2003) Functional excitatory synapses in HEK293 cells expressing neuroligin and glutamate receptors. J Neurophysiol 90:3950-3957. CrossRef Medline

Graf ER, Zhang X, Jin SX, Linhoff MW, Craig AM (2004) Neurexins induce differentiation of GABA and glutamate postsynaptic specializations via neuroligins. Cell 119:1013-1026. CrossRef Medline

Hines RM, Wu L, Hines DJ, Steenland H, Mansour S, Dahlhaus R, Singaraja RR, Cao X, Sammler E, Hormuzdi SG, Zhuo M, El-Husseini A (2008) Synaptic imbalance, stereotypies, and impaired social interactions in mice with altered neuroligin 2 expression. J Neurosci 28:6055-6067. CrossRef Medline

Irie M, Hata Y, Takeuchi M, Ichtchenko K, Toyoda A, Hirao K, Takai Y, Rosahl TW, Südhof TC (1997) Binding of neuroligins to PSD-95. Science 277:1511-1515. CrossRef Medline

Isaac JT, Nicoll RA, Malenka RC (1995) Evidence for silent synapses: implications for the expression of LTP. Neuron 15:427-434. CrossRef Medline

Jamain S, Quach H, Betancur C, Råstam M, Colineaux C, Gillberg IC, Soderstrom H, Giros B, Leboyer M, Gillberg C, Bourgeron T (2003) Mutations of the $\mathrm{X}$-linked genes encoding neuroligins NLGN3 and NLGN4 are associated with autism. Nat Genet 34:27-29. CrossRef Medline

Jin W, Ge WP, Xu J, Cao M, Peng L, Yung W, Liao D, Duan S, Zhang M, Xia J (2006) Lipid binding regulates synaptic targeting of PICK1, AMPA receptor trafficking, and synaptic plasticity. J Neurosci 26:2380-2390. CrossRef Medline

Kim HG, Kishikawa S, Higgins AW, Seong IS, Donovan DJ, Shen Y, Lally E, Weiss LA, Najm J, Kutsche K, Descartes M, Holt L, Braddock S, Troxell R, Kaplan L, Volkmar F, Klin A, Tsatsanis K, Harris DJ, Noens I, et al. (2008a) Disruption of neurexin 1 associated with autism spectrum disorder. Am J Hum Genet 82:199-207. CrossRef Medline

Kim J, Jung SY, Lee YK, Park S, Choi JS, Lee CJ, Kim HS, Choi YB, Scheiffele P, Bailey CH, Kandel ER, Kim JH (2008b) Neuroligin-1 is required for normal expression of LTP and associative fear memory in the amygdala of adult animals. Proc Natl Acad Sci U S A 105:9087-9092. CrossRef Medline

Kornau HC, Schenker LT, Kennedy MB, Seeburg PH (1995) Domain interaction between NMDA receptor subunits and the postsynaptic density protein PSD-95. Science 269:1737-1740. CrossRef Medline

Laumonnier F, Bonnet-Brilhault F, Gomot M, Blanc R, David A, Moizard MP, Raynaud M, Ronce N, Lemonnier E, Calvas P, Laudier B, Chelly J, Fryns JP, Ropers HH, Hamel BC, Andres C, Barthélémy C, Moraine C, Briault S (2004) X-linked mental retardation and autism are associated with a mutation in the NLGN4 gene, a member of the neuroligin family. Am J Hum Genet 74:552-557. CrossRef Medline 
Liao D, Hessler NA, Malinow R (1995) Activation of postsynaptically silent synapses during pairing-induced LTP in CA1 region of hippocampal slice. Nature 375:400-404. CrossRef Medline

Liao D, Zhang X, O'Brien R, Ehlers MD, Huganir RL (1999) Regulation of morphological postsynaptic silent synapses in developing hippocampal neurons. Nat Neurosci 2:37-43. CrossRef Medline

Lu W, Khatri L, Ziff EB (2014) Trafficking of alpha-amino-3-hydroxy-5methyl-4-isoxazolepropionic acid receptor (AMPA) receptor subunit GluA2 from the endoplasmic reticulum is stimulated by a complex containing $\mathrm{Ca} 2+/$ calmodulin-activated kinase II (CaMKII) and PICK1 protein and by release of $\mathrm{Ca} 2+$ from internal stores. J Biol Chem 289:19218-19230. CrossRef Medline

Meyer G, Varoqueaux F, Neeb A, Oschlies M, Brose N (2004) The complexity of PDZ domain-mediated interactions at glutamatergic synapses: a case study on neuroligin. Neuropharmacology 47:724-733. CrossRef Medline

Missler M, Zhang W, Rohlmann A, Kattenstroth G, Hammer RE, Gottmann K, Südhof TC (2003) Alpha-neurexins couple Ca2 + channels to synaptic vesicle exocytosis. Nature 423:939-948. CrossRef Medline

Mondin M, Labrousse V, Hosy E, Heine M, Tessier B, Levet F, Poujol C, Blanchet C, Choquet D, Thoumine O (2011) Neurexin-neuroligin adhesions capture surface-diffusing AMPA receptors through PSD-95 scaffolds. J Neurosci 31:13500-13515. CrossRef Medline

Nam CI, Chen L (2005) Postsynaptic assembly induced by neurexinneuroligin interaction and neurotransmitter. Proc Natl Acad Sci U S A 102:6137-6142. CrossRef Medline

Perez JL, Khatri L, Chang C, Srivastava S, Osten P, Ziff EB (2001) PICK1 targets activated protein kinase $\mathrm{C} \alpha$ to AMPA receptor clusters in spines of hippocampal neurons and reduces surface levels of the AMPA-type glutamate receptor subunit 2. J Neurosci 21:5417-5428. Medline

Scheiffele P, Fan J, Choih J, Fetter R, Serafini T (2000) Neuroligin expressed in nonneuronal cells triggers presynaptic development in contacting axons. Cell 101:657-669. CrossRef Medline

Sossa KG, Court BL, Carroll RC (2006) NMDA receptors mediate calcium- dependent, bidirectional changes in dendritic PICK1 clustering. Mol Cell Neurosci 31:574-585. CrossRef Medline

Steinberg JP, Takamiya K, Shen Y, Xia J, Rubio ME, Yu S, Jin W, Thomas GM, Linden DJ, Huganir RL (2006) Targeted in vivo mutations of the AMPA receptor subunit GluR2 and its interacting protein PICK1 eliminate cerebellar long-term depression. Neuron 49:845-860. CrossRef Medline

Tabuchi K, Blundell J, Etherton MR, Hammer RE, Liu X, Powell CM, Südhof TC (2007) A neuroligin-3 mutation implicated in autism increases inhibitory synaptic transmission in mice. Science 318:71-76. CrossRef Medline

Terashima A, Pelkey KA, Rah JC, Suh YH, Roche KW, Collingridge GL, McBain CJ, Isaac JT (2008) An essential role for PICK1 in NMDA receptor-dependent bidirectional synaptic plasticity. Neuron 57:872882. CrossRef Medline

Varoqueaux F, Aramuni G, Rawson RL, Mohrmann R, Missler M, Gottmann K, Zhang W, Südhof TC, Brose N (2006) Neuroligins determine synapse maturation and function. Neuron 51:741-754. CrossRef Medline

Wenthold RJ, Petralia RS, Blahos J II, Niedzielski AS (1996) Evidence for multiple AMPA receptor complexes in hippocampal CA1/CA2 neurons. J Neurosci 16:1982-1989. Medline

Xia J, Zhang X, Staudinger J, Huganir RL (1999) Clustering of AMPA receptors by the synaptic PDZ domain-containing protein PICK1. Neuron 22:179-187. CrossRef Medline

Xia J, Chung HJ, Wihler C, Huganir RL, Linden DJ (2000) Cerebellar longterm depression requires PKC-regulated interactions between GluR2/3 and PDZ domain-containing proteins. Neuron 28:499-510. CrossRef Medline

Yan J, Feng J, Schroer R, Li W, Skinner C, Schwartz CE, Cook EH Jr, Sommer SS (2008a) Analysis of the neuroligin $4 \mathrm{Y}$ gene in patients with autism. Psychiatr Genet 18:204-207. CrossRef Medline

Yan J, Noltner K, Feng J, Li W, Schroer R, Skinner C, Zeng W, Schwartz CE, Sommer SS (2008b) Neurexin lalpha structural variants associated with autism. Neurosci Lett 438:368-370. CrossRef Medline 